\title{
高职机电一体化技术专业《工业机器人操作与编程》课程改革探 索
}

龚成武

重庆机电职业技术大学

DOI:10.32629/er.v3i5.2749

[摘 要] 中国智能制造2025的影响下,当前越来越多的企业开始智能制造转型升级,企业对传统机电专业毕业生的工业机器人操作与编程技能 需求不断提升, 在这样的背景下, 《工业机器人操作与编程》被写入到高等职业院校机电一体化技术专业教学标准内, 并作为专业核心课程之一, 本文讲述了重庆机电职业技术大学针对高职机电一体化技术专业学生开设的《工业机器人操作与编程》课程改革探索, 确立教学目标, 创新课程 教学内容, 丰富课程配套资源, 提升学生学习兴趣, 增强学生知识的获得感。

[关键词] 机电一体化技术; 工业机器人操作与编程; 课程改革探索

\section{引言}

2014年6月, 习近平总书记在两院院士大会上强调: “机器人革命” 有 望成为“第三次工业革命”的一个切入点和重要增长点。在《中国制造2025》 规划中, 工业机器人是十大重点发展方向之一。2016年3月21日, 工业和信 息化部、发展改革委、财政部正式印发的《机器人产业发展规划 (2016-2020)》, 为 “十三五” 期间我国机器人产业发展描绘了清晰的蓝图, 改规划中明确了急需加强大专院校机器人相关专业学科建设, 加大工业机 器人职业培训教育力度, 注重专业人才培养, 着力与应用型人才队伍建设。 国家政策的刺激, 使得越来越受到企业的重视智能制造改造升级, 在工业 生产的各个领域中, 工业机器人应用越来越多, 工业机器人能够降低生产 成本, 提高生产效率的优势日益突出, 而对于具备工业机器人技术应用知 识的人才需求缺口越来越大, 工业机器人技术类人才供不应求。2 2019 年 7 月 30 日, 教育部职业教育与成人教育司发布了最新的高等职业学校专业教 学标准, 明确将 《工业机器人操作与编程》作为机电一体化技术专业的专 业核心课程之一。在这样的背景下, 针对我校的传统优势机电一体化技术 专业, 结合专业调研情况, 我们对机电一体化技术专业人才培养方案做了 调整, 并对《工业机器人操作与编程》专业课程进行了改革探索。

\section{1 课程改革的可行性分析及课程内容定位}

\section{1 可行性分析}

我国高职院校2015年开始才开始开设工业机器人技术专业, 真正工业 机器人技术专业的毕业生远远满足不了市场需求。在进行课程改革前, 我 们做了一定的市场调研, 目前大部分的工业机器人操作与编程技术人员, 主要还是从原来的机电一体化技术、电气自动化技术或数控技术专业毕业 学生转行而来的。由此可见学习机电一体化技术或其他相近专业, 通过一 定的工业机器人相关内容学习, 也能满足企业对工业机器人操作与编程技 术人员的需求。传统的机电一体化技术专业与工业机器人技术专业, 在专 业基础课程方面, 有很多相近的课程, 这为机电一体化技术专业学生学习 掌握工业机器人相关知识提供了理论支撑。由此可见, 在机电一体化技术 专业开设《工业机器人编程与操作》课程是可行的。

\section{2课程内容定位}

高职机电一体化技术专业的《工业机器人编程与操作》课程内容与工 业机器人技术专业的该门课程内容略有不同。工业机器人技术专业学生, 在学习该门课程之前, 已经学习并掌握了一定的工业机器人技术基础理论 知识, 在学习工业机器人操作与编程内容时, 不用再考虑诸如: 机器人发展 历史, 机器人分类、机器人坐标系、机器人结构等知识内容的学习, 而机电
一体化技术专业的学生, 则没有工业机器人技术基础知识, 相当于是初学 者的身份。针对以上情况, 我们对《工业机器人编程操作》课程内容定位 为: 初学者, 或初次接触工业机器人的人员学习。知识结构方面融入: 工 业机器人基础内容、工业机器人安全操作、工业机器人手动编程和离线编 程等内容, 旨在让学生通过该门课程的学习快速掌握工业机器人的基本知 识, 并能对工业机器人进行典型应用进行操作与编程。

\section{2 课程改革的措施}

根据企业调研及课程定位, 我们对课程的教学目标、教学内容、教学 资源做了相应的规划。教学目标明确了开设《工业机器人编程与操作》课 程后, 教授机电一体化技术专业学生需达到的知识、能力、素质目标。教 学内容方面, 我们根据本专业学生的知识结构特点并结合企业用人需求, 增设了工业机器人基础知识讲解, 在机器人的操作编程知识方面, 选取目 前功能和稳定性较好的ABB工业机器人为主要讲授对象。在课程配套资源 建设方面, 组建了专门的教师团队, 开发对应的教材, 由团队开发制作配套 的教学PPT、微课、虚拟工作平台等资源。

\section{1课程教学目标 \\ 2.1. 1 知识目标}

通过学习, 让机电一体化技术专业学生了解机器人的由来与发展、组 成与技术参数; 掌握机器人分类与应用, 对各类机器人有较系统的完整认 识; 了解机器人本体基本结构, 包括机身及臂部结构、腕部及手部结构、 传动及行走机构等; 掌握工业机器人控制系统的基本构成及操作方法; 掌 握机器人语言的基本程序命令和编程方法; 熟悉工业机器人典型应用自动 线; 了解工业机器人的离线编程。

\subsection{2能力目标}

通过课程内容的学习, 让机电一体化技术专业学生能够对机器人发展 有一定的认识; 能够准确理解机器人本体的基本构成; 会查阅相关手册和 产品使用说明书, 正确阅读和分析实际应用程序; 能对常见ABB的工业机器 人工作站进行手动操作; 能够用示教器对ABB的工业机器人工作站编制、 调试、运行程序; 能够运用Robotstudio软件进行离线编程。

\subsection{3素质目标}

培养学生有坚定正确的政治方向, 热爱祖国, 拥护中国共产党的领导; 培养学生对机器人的兴趣, 培养学生关心科技、热爱科学、勇于探索的精 神; 培养科学的学习态度与作风, 利用先进技术进行开拓创新的专业思维; 培养良好的专业触觉; 培养搜集相关技术资料, 尽快熟悉新接触设备和新 工作场景的能力; 培养独立学习, 灵活运用所学知识独立分析问题并解决 
问题的能力; 培养工作安全意识与自我保护能力; 培养团队协作能力。 2. 2 课程内容

根据教学目标要求, 我们将《工业机器人操作与编程》这门课程教授 内容进行了划分, 按照学生获取知识的规律, 我们将课程主要分为工业机 器人兴趣技术、操作与编程基础、应用实例、拓展技术应用 4 大板块, 设立 了 9 个模块 30 个项目。模块 1 厉害了我的机器人: 介绍了市面上常见的各类 有趣的机器人, 如: 波士顿动力公司的大狗, 物流机器人, 美女机器人佳佳 等; 模块 2 机器人时代: 从生活中、影视作品、小说中的机器人引入, 讲述 什么是机器人、机器人的分类、机器人的发展等知识; 模块 3 工业机器长 什么样: 主要讲授工业机器的结构、分类、典型应用领域, 为工业机器人 技术理论基础知识; 模块 4 触摸工业机器人: 通过动手自制一台 6 轴工业机 器人模型, 以及如何用工业机器人来表达爱, 编制一个简单的程序绘制一 颗爱心; 模块5怎样操作机器人: 工业机器人的安全操作, 如安全着装, 操 作规范等, ABB工业机器人示教器的基本操作与示教器的编程操作前的设 定工作; 模块 6 工业机器人怎样通讯: ABB工业机器人的I $/ 0$ 通讯模块相关 知识内容; 模块7工业机器人怎样编程: ABB工业机器人的编程常用指令讲 解; 模块 8 工业机器人编程实例: ABB工业机器人的简单轨迹编程、码垛、 焊接、综合搬运典型应用程序编写; 模块 9 工业机器人拓展: 如何用 $A B B$ 手册及光盘查询获取想要的技术资料, 如何利用robotstudio离线仿真软 件绘制一件个性T恤等。

课程内容设计亮点, 结合新时代学生的特点以及教学认知规律, 编入 了贴近生活、更有趣味、更加时尚科技的内容。让学生自己用身边触手可 及的材料, 自己动手制作一台属于自己的6轴工业机器人, 进一步加深学生 对6轴工业机器人结构组成的理解。在操作机器人方面, 从企业安全生产的 角度出发, 讲授常见的安全标示、安全着装、日常机器人安全操作规范内 容, 随后由浅入深逐步讲解ABB工业机器人的操作与编程基础、应用实例、 拓展等知识点。

\section{3课程改革具体实施}

\subsection{1资源建设}

在课程资源建设方面, 首先结合课程内容知识模块, 组建专门的教学 团队, 编写了与模块内容对应的 《工业机器人编程与操作》教材, 并编写教 学用的PPT。结合当下学生获取知识的特点, 教学团队开发了微小知识点讲 解视频, 时间都控制在1-2分钟以内。通过三维建模软件, 将工作站以及工
业机器人模型制作成可在线浏览的内容。针对操作与编程基础、应用实例、 拓展技术三大板块, 结合工业机器人实训室现有实训设备, 我们利用 Robotstudio6. 08仿真软件, 搭建虚实结合的操作平台, 解决了实训设备少 与学生学习人数多的难题。

\subsection{2课程改革效果}

目前我校2019级以及 2020 级机电一体化技术专业人才培养方案中, 均 设立了《工业机器人操作与编程》课程, 按照课程改革的内容, 本学期对 2019级的学生进行了线上授课, 目前学生普遍反应教学内容有趣, 对工业 机器人操作与编程产生浓厚的学习兴趣, 对教师讲授的工业机器人相关知 识印象深刻。

\section{3 课程改革总结}

依据国家的职业教育专业教学标准, 通过对企业走访调研和人才市场 分析, 明确了机电一体化技术专业《工业机器人操作与编程》课程改革的 可行性与课程内容定位, 在课程内容设置方面, 我们将这门核心专业课程 划分为: 4 大板块 9 个模块 30 个项目 100 个微小知识点, 课程配套资源方面, 组建专业教学团队, 按照课程设置内容编写了对应的教材, 并辅以PPT, 微 课, 抖音小视频, 工业机器人工业应用案例视频等, 以有趣、轻松、贴近生 活的方式, 让机电一体化技术专业学生在学习该门专业核心课程中, 具有 更好的体验和获得感。

[参考文献]

[1]国家制造强国建设战略咨询委员会《中国制造2025》重点领域技术路线 图(2015年版)[EB/OL].http://www.cm2025.org/show-16-90-1.htm77(2016-03-21).

[2]蒋庆斌,陈小艳,周斌.工业机器人行业人才需求与高职院校专业设 置分析研究 [J].职业技术教育研究,2018(02):27-30.

[3]高等职业教育教学标准[S].2019-07-30.

[4]王芳,赵中宁, 张良智, 等. 智能制造背景下技术技能人才需求变化的 调研与分析[J].中国职业技术教育,2017(11):18-27.

[5]张春芝,钟柱培, 许奸妩.工业机器人操作与编程[M].2018.

\section{作者简介：}

龚成武(1981--), 男, 汉族, 四川资阳人, 工程师/讲师, 本科学士, 重 庆机电职业技术大学,研究方向: 非标自动化设计、工业机器人技术、 柴油发动机研发等。 